\title{
Comparing Non-Vitamin K Antagonist Oral Anticoagulants (NOACs) to Different Coumadins: The Win-Win Scenarios
}

\author{
Tatjana S. Potpara ${ }^{1,2}$ \\ ${ }^{1}$ School of Medicine, Belgrade University, Belgrade, Serbia \\ ${ }^{2}$ Cardiology Clinic, Clinical Centre of Serbia, Belgrade, Serbia \\ Thromb Haemost 2018;118:803-805.
}

\begin{abstract}
Address for correspondence Tatjana Potpara, MD, PhD, FESC, Cardiology Clinic, Clinical Center of Serbia, Visegradska 26, Belgrade 11000, Serbia

(e-mail: tanjapotpara@gmail.com; tatjana.potpara@med.bg.ac.rs).
\end{abstract}

In addition to warfarin, the family of vitamin $\mathrm{K}$ antagonist (VKA) oral anticoagulants includes acenocoumarol, phenprocoumon, phenindione and fluindione. ${ }^{1}$ These drugs alter the functionality of vitamin K-dependent coagulation factors II, VII, IX and $\mathrm{X}$ and anticoagulant proteins $\mathrm{C}, \mathrm{S}$ and $\mathrm{Z}$ by inhibiting the vitamin K epoxide reductase complex subunit 1 (VKORC1), while non-vitamin K antagonist oral anticoagulants (NOACs) directly inhibit a single coagulation factor (i.e. dabigatran inhibits factor II, and rivaroxaban, apixaban and edoxaban inhibit activated factor X). ${ }^{2}$ All NOACs exhibit a stable, dose-related anticoagulant effect with no food-drug and less drug-drug interactions than VKAs and are used in fixed doses without routine laboratory monitoring of anticoagulant effect or food restrictions. ${ }^{1,2}$ In a meta-analysis of the four landmark randomized clinical trials (RCTs) of NOACs versus warfarin in patients with atrial fibrillation (AF), NOACs were associated with a significant $19 \%$ relative risk reduction (RRR) in any stroke or systemic embolism (SSE), a significant 10\% RRR in all-cause mortality and a 14\% RRR in major bleeding $(p=0.06){ }^{3}$ Importantly, all NOACs consistently reduced haemorrhagic stroke or any intracranial bleeding for $>50 \%$ (both $p<0.0001$ ). ${ }^{3}$

Owing to these advantages, international AF guidelines now recommend NOACs as the first-choice treatment or a viable alternative to VKAs in patients with AF at increased risk of stroke (excluding those with a mechanical heart valve or rheumatic mitral stenosis). ${ }^{4,5}$ With increasing use of NOACs in clinical practice, ${ }^{6}$ the real-world evidence (RWE) of their effectiveness and safety relative to warfarin rapidly accumulates, ${ }^{7-10}$ broadly confirming the results of NOAC landmark trials (see - Table $\mathbf{1}$ ). ${ }^{11}$

Although warfarin is the most commonly used VKA worldwide, in some countries other VKAs are more often prescribed (e.g. acenocoumarol in Spain or Germany, phenprocoumon in Germany, Austria, Denmark, Switzerland, the Netherlands and
Brazil, and fluindione in France), ${ }^{12}$ and there are clinically relevant differences among these drugs. For example, some VKAs have a short half-life of $\leq 12$ hours (i.e. phenindione 510 hours, acenocoumarol 8-11 hours), while others have an intermediate (warfarin 40 hours [range, 20-60], fluindione 31 hours) or a long half-life (phenprocoumon 110-130 hours). The effects of CYP2C9 polymorphisms on the stability of anticoagulant effect are less evident with phenprocoumon than warfarin or acenocoumarol, which results in a more stable anticoagulant effect of phenprocoumon, requiring less frequent laboratory monitoring and dose adjustments. ${ }^{13}$

How do NOACs compare with these VKAs? In this issue of Thrombosis Haemostasis, Hohnloser et $\mathrm{al}^{14}$ reported the first retrospective observational comparison of the effectiveness and safety of dabigatran, rivaroxaban and apixaban versus phenprocoumon in a large anticoagulant-naïve AF cohort ( $n=61,205)$, and their findings were broadly consistent with results of the pivotal RCTs ${ }^{3}$ and $\mathrm{RWE}^{11}$ comparing NOACs versus warfarin (see - Table 1). Similarly, a small propensity score-matched retrospective study of VKA-naïve AF patients $(n=766)$ starting dabigatran or acenocoumarol ${ }^{15}$ and a nationwide retrospective matched-cohort study of VKAexperienced AF patients $(n=17,410)$ taking fluindione or switching to dabigatran or rivaroxaban ${ }^{16}$ provided a reassuring RWE on the NOACs performance relative to acenocoumarol and fluindione, respectively (see - Table 1).

The study of Hohnloser et al $^{14}$ also provided an insight into the effectiveness and safety of reduced NOACs doses compared with phenprocoumon. Interestingly, the use of dabigatran $110 \mathrm{mg}$ or rivaroxaban $15 \mathrm{mg}$ in their study was close to that in the RE-LY (51\% vs. $49.7 \%)^{17}$ or ROCKET AF ( $28 \%$ vs. $20.7 \%)^{18}$ trial, while the use of apixaban $2.5 \mathrm{mg}$ was much higher than in the ARISTOTLE trial (37\% vs. $4.5 \%) .{ }^{19}$ Since reduced NOACs doses were preferentially prescribed to older and sicker patients who were likely good candidates for received

February 28, 2018

accepted

February 28, 2018
Copyright (c) 2018 Schattauer

DOI https://doi.org/ $10.1055 / \mathrm{s}-0038-1641166$. ISSN 0340-6245. 
Table 1 The effectiveness and safety of NOACs compared with various VKAs in the real-world observational studies

\begin{tabular}{|c|c|c|c|c|c|}
\hline Outcome & Study setting & $\begin{array}{l}\text { Dabigatran }^{a} \\
\text { HR }(95 \% \mathrm{CI})\end{array}$ & $\begin{array}{l}\text { Rivaroxaban } \\
\text { HR }(95 \% \mathrm{Cl})\end{array}$ & $\begin{array}{l}\text { Apixaban } \\
\text { HR }(95 \% \mathrm{Cl})\end{array}$ & Comparator \\
\hline \multirow[t]{5}{*}{$\begin{array}{l}\text { Stroke or systemic } \\
\text { embolism }\end{array}$} & $\mathrm{RCT}^{\mathrm{b}}$ & $\begin{array}{l}0.66(0.53-0.82) \\
0.91(0.74-1.11)\end{array}$ & $0.88(0.75-1.03)$ & $0.79(0.66-0.95)$ & Warfarin \\
\hline & \multirow[t]{4}{*}{ RWE } & $0.93(0.77-1.14)$ & $0.87(0.71-1.07)$ & $0.67(0.46-0.98)$ & Warfarin $^{11}$ \\
\hline & & $\begin{array}{l}0.48(0.32-0.72) \\
0.89(0.70-1.13)\end{array}$ & $0.89(0.77-1.02)$ & $0.77(0.64-0.93)$ & Phenprocoumon $^{14}$ \\
\hline & & $0.73(0.21-2.55)$ & NR & NR & Acenocoumarol $^{15, c}$ \\
\hline & & $1.10(0.70-1.73)$ & $0.75(0.39-1.45)$ & NR & Fluindione $^{16, d}$ \\
\hline \multirow[t]{3}{*}{ Ischaemic stroke } & $\mathrm{RCT}^{\mathrm{b}}$ & $\begin{array}{l}0.76(0.60-0.98) \\
1.11(0.89-1.40)\end{array}$ & $0.94(0.75-1.17)$ & $0.92(0.74-1.13)$ & Warfarin \\
\hline & \multirow[t]{2}{*}{ RWE } & $0.96(0.80-1.16)$ & $0.89(0.76-1.04)$ & $0.95(0.75-1.19)$ & Warfarin $^{11}$ \\
\hline & & $\begin{array}{l}0.52(0.32-0.83) \\
1.05(0.80-1.38)\end{array}$ & $0.91(0.77-1.07)$ & $0.82(0.66-1.03)$ & Phenprocoumon $^{14}$ \\
\hline \multirow[t]{3}{*}{ All-cause death } & $\mathrm{RCT}^{\mathrm{b}}$ & $\begin{array}{l}0.88(0.77-1.00) \\
0.91(0.80-1.03)\end{array}$ & $0.85(0.70-1.02)$ & $0.89(0.80-0.998)$ & Warfarin \\
\hline & \multirow[t]{2}{*}{ RWE } & $0.63(0.52-0.79)$ & $0.67(0.35-1.30)$ & $0.65(0.56-0.75)$ & Warfarin $^{11}$ \\
\hline & & $\begin{array}{l}0.92(0.84-1.01) \\
1.17(1.07-1.27)\end{array}$ & $1.12(1.04-1.21)$ & $1.05(0.94-1.17)$ & Phenprocoumon $^{14}$ \\
\hline \multirow[t]{5}{*}{ Major bleeding } & $\mathrm{RCT}^{\mathrm{b}}$ & $\begin{array}{l}0.93(0.81-1.07) \\
0.80(0.69-0.93)\end{array}$ & $1.04(0.90-1.20)$ & $0.69(0.60-0.80)$ & Warfarin \\
\hline & \multirow[t]{4}{*}{ RWE } & $0.83(0.65-1.05)$ & $1.00(0.92-1.08)$ & $0.55(0.48-0.63)$ & Warfarin $^{11}$ \\
\hline & & $\begin{array}{l}0.47(0.30-0.74) \\
0.72(0.55-0.94)\end{array}$ & $1.09(0.96-1.23)$ & $0.58(0.48-0.71)$ & Phenprocoumon $^{14}$ \\
\hline & & $0.44(0.21-0.93)$ & NR & NR & Acenocoumarol $^{15, c}$ \\
\hline & & $0.79(0.57-1.09)$ & $1.11(0.74-1.66)$ & NR & Fluindione $^{16, \mathrm{~d}}$ \\
\hline \multirow[t]{3}{*}{$\mathrm{ICH}$} & $\mathrm{RCT}^{\mathrm{b}}$ & $\begin{array}{l}0.40(0.27-0.60) \\
0.31(0.20-0.47)\end{array}$ & $0.67(0.47-0.93)$ & $0.42(0.30-0.58)$ & Warfarin \\
\hline & \multirow[t]{2}{*}{ RWE } & $0.42(0.37-0.49)$ & $0.64(0.47-0.86)$ & $0.45(0.31-0.63)$ & Warfarin $^{11}$ \\
\hline & & $\begin{array}{l}0.28(0.10-0.77) \\
0.66(0.39-1.12)\end{array}$ & $0.74(0.57-0.97)$ & $0.39(0.25-0.60)$ & Phenprocoumon $^{14}$ \\
\hline \multirow[t]{3}{*}{ GI bleeding } & $\mathrm{RCT}^{\mathrm{b}}$ & $\begin{array}{l}1.50(1.19-1.89) \\
1.10(0.86-1.41)\end{array}$ & $1.66(1.34-2.05)$ & $0.89(0.70-1.15)$ & Warfarin \\
\hline & \multirow[t]{2}{*}{ RWE } & $1.20(1.06-1.36)$ & $1.24(1.08-1.41)$ & $0.63(0.42-0.95)$ & Warfarin $^{11}$ \\
\hline & & $\begin{array}{l}1.26(1.11-1.42) \\
1.26(1.10-1.45)\end{array}$ & $1.35(1.20-1.51)$ & $0.71(0.59-0.85)$ & Phenprocoumon $^{14}$ \\
\hline
\end{tabular}

Abbreviations: AF, atrial fibrillation; $\mathrm{Cl}$, confidence interval; $\mathrm{Gl}$, gastrointestinal; $\mathrm{HR}$, hazard ratio; ICH, intracranial haemorrhage; NOAC, non-vitamin $\mathrm{K}$ antagonist oral anticoagulant; NR, not reported; RCT, randomized clinical trial; RWE, real-world evidence; VKA, vitamin K antagonist.

${ }^{a}$ Where available, data are given for dabigatran $150 \mathrm{mg}$ twice a day in the upper row, and dabigatran $110 \mathrm{mg}$ twice a day in the lower row.

${ }^{b}$ The efficacy/safety of each NOAC in the respective landmark RCT.

'A small retrospective observational cohort of anticoagulant-naïve AF patients $(n=766)$. Patients taking dabigatran or acenocoumarol were paired using propensity score matching.

${ }^{\mathrm{d}}$ A nationwide, retrospective, matched-cohort observational study of VKA-experienced patients $(n=17,410)$, with 10,705 patients non-switching to a NOAC $(9,688 / 10,705[90 \%]$ on fluindione).

reduced NOAC doses, that could perhaps explain the comparable effectiveness and safety of reduced and standard NOACs doses relative to phenprocoumon. ${ }^{14}$ In general, the choice of NOACs dose should be determined by the patient's age, renal function and body weight or concomitant treatment with interacting drugs. Unfortunately, data on renal function were not available in the study of Hohnloser et al, and the appropriateness of NOAC dosing could not be ascertained. However,
NOACs dosing inconsistent with drug labelling has been associated with worse outcomes compared with proper dosing. ${ }^{20}$

Although the observations reported by Hohnloser et al were confirmed in two pre-specified sensitivity analyses, reflecting their robustness to the various model assumptions, ${ }^{14}$ the RWE gathered from post-approval observational studies should always be interpreted with caution, taking into account their numerous limitations arising from the 
study design, selection bias, cohort size, residual confounding, follow-up duration, study endpoint(s) definition and event adjudication, data completeness, statistical methods used for data analyses, etc. ${ }^{21}$ Nevertheless, the increasing RWE on the effectiveness and safety of NOACs in comparison to different VKAs, with reported risk ratios being very similar to those in the landmark RCTs, is generally reassuring and suggest that NOACs are performing comparably well in clinical practice as in the respective RCTs. More data are needed to optimize the use of NOACs in 'special' AF populations such as, for example, the elderly, patients on chronic dialysis or those with active malignancy.

Conflicts of interest

None declared.

\section{References}

1 De Caterina R, Husted S, Wallentin L, et al. Vitamin K antagonists in heart disease: current status and perspectives (Section III). Position paper of the ESC Working Group on Thrombosis-Task Force on Anticoagulants in Heart Disease. Thromb Haemost 2013; 110(06):1087-1107

2 Weitz JI, Harenberg J. New developments in anticoagulants: past, present and future. Thromb Haemost 2017;117(07):1283-1288

3 Ruff CT, Giugliano RP, Braunwald E, et al. Comparison of the efficacy and safety of new oral anticoagulants with warfarin in patients with atrial fibrillation: a meta-analysis of randomised trials. Lancet 2014;383(9921):955-962

4 Lip G, Freedman B, De Caterina R, Potpara TS. Stroke prevention in atrial fibrillation: past, present and future. Comparing the guidelines and practical decision-making. Thromb Haemost 2017;117 (07):1230-1239

5 Lip GYH, Collet JP, de Caterina R, et al. Antithrombotic therapy in atrial fibrillation associated with valvular heart disease: executive summary of a Joint Consensus Document from the European Heart Rhythm Association (EHRA) and European Society of Cardiology Working Group on Thrombosis, Endorsed by the ESC Working Group on Valvular Heart Disease, Cardiac Arrhythmia Society of Southern Africa (CASSA), Heart Rhythm Society (HRS), Asia Pacific Heart Rhythm Society (APHRS), South African Heart (SA Heart) Association and Sociedad Latinoamericana de Estimulación Cardíaca y Electrofisiología (SOLEACE). Thromb Haemost 2017;117(12):2215-2236

6 Mazurek M, Huisman MV, Rothman KJ, et al; GLORIA-AF Investigators. Regional differences in antithrombotic treatment for atrial fibrillation: insights from the GLORIA-AF Phase II Registry. Thromb Haemost 2017;117(12):2376-2388

7 Potpara TS. Dabigatran in 'real-world' clinical practice for stroke prevention in patients with non-valvular atrial fibrillation. Thromb Haemost 2015;114(06):1093-1098
8 Li XS, Deitelzweig S, Keshishian A, et al. Effectiveness and safety of apixaban versus warfarin in non-valvular atrial fibrillation patients in "real-world" clinical practice. A propensity-matched analysis of 76,940 patients. Thromb Haemost 2017;117(06): 1072-1082

9 Hecker J, Marten S, Keller L, et al. Effectiveness and safety of rivaroxaban therapy in daily-care patients with atrial fibrillation. Results from the Dresden NOAC Registry. Thromb Haemost 2016; 115(05):939-949

10 Lip GY, Keshishian A, Kamble S, et al. Real-world comparison of major bleeding risk among non-valvular atrial fibrillation patients initiated on apixaban, dabigatran, rivaroxaban, or warfarin. A propensity score matched analysis. Thromb Haemost 2016;116(05):975-986

11 Ntaios G, Papavasileiou V, Makaritsis K, Vemmos K, Michel P, Lip GYH. Real-world setting comparison of nonvitamin-K antagonist oral anticoagulants versus vitamin-K antagonists for stroke prevention in atrial fibrillation: a systematic review and metaanalysis. Stroke 2017;48(09):2494-2503

12 Le Heuzey JY, Ammentorp B, Darius H, et al. Differences among western European countries in anticoagulation management of atrial fibrillation. Data from the PREFER IN AF registry. Thromb Haemost 2014;111(05):833-841

13 Fihn SD, Gadisseur AA, Pasterkamp E, et al. Comparison of control and stability of oral anticoagulant therapy using acenocoumarol versus phenprocoumon. Thromb Haemost 2003;90(02):260-266

14 Hohnloser SH, Basic E, Hohmann C, Nabauer M. Effectiveness and safety of non-vitamin $\mathrm{K}$ oral anticoagulants in comparison to phenprocoumon: data from 61,000 patients with atrial fibrillation. Thromb Haemost 2018;118(03):526-538

15 Korenstra J, Wijtvliet EP, Veeger NJ, et al. Effectiveness and safety of dabigatran versus acenocoumarol in 'real-world' patients with atrial fibrillation. Europace 2016;18(09):1319-1327

16 Bouillon K, Bertrand M, Maura G, Blotière PO, Ricordeau P, Zureik M. Risk of bleeding and arterial thromboembolism in patients with non-valvular atrial fibrillation either maintained on a vitamin K antagonist or switched to a non-vitamin K-antagonist oral anticoagulant: a retrospective, matched-cohort study. Lancet Haematol 2015;2(04):e150-e159

17 Connolly SJ, Ezekowitz MD, Yusuf S, et al; RE-LY Steering Committee and Investigators. Dabigatran versus warfarin in patients with atrial fibrillation. N Engl J Med 2009;361(12):1139-1151

18 Patel MR, Mahaffey KW, Garg J, et al; ROCKET AF Investigators. Rivaroxaban versus warfarin in nonvalvular atrial fibrillation. $\mathrm{N}$ Engl J Med 2011;365(10):883-891

19 Granger CB, Alexander JH, McMurray JJ, et al; ARISTOTLE Committees and Investigators. Apixaban versus warfarin in patients with atrial fibrillation. N Engl J Med 2011;365(11):981-992

20 Yao X, Shah ND, Sangaralingham LR, Gersh BJ, Noseworthy PA, Non-Vitamin K. Non-vitamin $\mathrm{K}$ antagonist oral anticoagulant dosing in patients with atrial fibrillation and renal dysfunction. J Am Coll Cardiol 2017;69(23):2779-2790

21 Potpara TS, Lip GY. Postapproval observational studies of nonvitamin $\mathrm{K}$ antagonist oral anticoagulants in atrial fibrillation. JAMA 2017;317(11):1115-1116 